\title{
Meaning Reconstruction in the Wake of Loss: Evolution of a Research Program
}

\author{
Robert A. Neimeyer \\ University of Memphis, Memphis, Tennessee, USA
}

\begin{abstract}
As theories of bereavement have evolved, so too have evidence-based interventions to mitigate complications in post-loss adaptation. This article reviews one line of programmatic research grounded in a conceptualisation of grieving as an attempt to reaffirm or reconstruct a world of meaning challenged by loss. Anchored in therapeutic encounters with the bereaved, a meaning reconstruction approach to loss has grown over the past 15 years to generate an increasingly substantial research base, as well as to develop and refine a wide array of contributions to psychological assessment and therapy. By summarising the major models, measures and methods resulting from this collaborative work, it offers an introduction to meaning reconstruction for those unfamiliar with it, noting its contributions to date, its areas of future development, and its relevance for clinical practice.
\end{abstract}

Keywords: grief therapy, bereavement, meaning reconstruction, spiritual struggle

At the point that Linda sought therapy, some six months after the death of her fiancé, Mark, in a tragic boating accident, she described herself as 'depressed and hopeless', in a seemingly meaningless cycle of 'wake up and repeat' days that did not 'really feel like living'. Although she acknowledged the well-intentioned support of friends, Mark's death renewed her cynicism cultivated by disappointing past relationships, and left her 'drowning' in the 'black hole' that accompanied his absence. Compounding her pervasive grief, intrusive images of the accident itself (e.g., Mark's floating face down, neck broken after his reckless dive in the shallow cove of the lake in which they had anchored) and the four days of critical care that followed (e.g., his inability to move his limbs, his fearful agitation, his mechanical ventilation) crowded into her thoughts and dreams, adding a dimension of traumatic hyperarousal to a 'surreal' experience that appeared unbearable. Though not actively suicidal, she found herself wondering 'whether living was worth it', as all joy seemed to have died with the man she loved.

Most of all, Linda found herself ruminatively 'replaying' the circumstances of Mark's accident, the period of his hospitalisation, and her anguished decision to remove him from the ventilator following his brain death and the corrosive guilt it engendered. Swirling around each of these was a welter of haunting questions about whether she could have foreseen or prevented the accident, whether Mark realised he was dying, and whether she should have made different decisions about his treatment. More basic than any of these were the unanswerable questions, 'Why me? Why us?' As a religious person, Linda described her inability to discern God's will as precipitating a spiritual crisis for her, her anger at God leading to her to withdraw from contact with a being and a faith community that no longer felt trustworthy, loving and reliable.

Address for correspondence: Robert A. Neimeyer, University of Memphis, Memphis, Tennessee, USA.

Email: neimeyer@memphis.edu. Readers interested in reading more about meaning-oriented research and practice are encouraged to browse the author's web site at robertneimeyerphd.com

Behaviour Change | Volume 33 | Number 2 | 2016 | pp. 65-79 | (C) The Author(s) 2016

doi $10.1017 /$ bec.2016.4 
Mark's death, Linda reported, 'shattered her whole world view', leaving her bitterly preoccupied with her grief, disengaged from her previously satisfying work as a geriatric nurse, and unable to envision a future of renewed love and purpose.

Long relegated to a position of relative neglect within psychological theory and research, the study of bereavement adaptation following the death of an attachment figure has recently emerged as a vital area of investigation, yielding fresh perspectives on grieving and its complications (Neimeyer, 2016a). As a result, current conceptualisations of grief involving dual processes of coping with the loss versus adapting to a changed life (Stroebe \& Schut, 2010), reorganising 'working models' of attachment in the wake of a loved one's death (Kosminsky \& Jordan, 2016), and managing biopsychosocial symptomatology and challenges in the continuing bond with the deceased (Rubin, Malkinson, \& Witztum, 2011) have come to supplement and gradually supplant less scientifically based theories focusing on putative stages of grieving or presumptions that adaptation to loss involves a gradual withdrawal of emotional investment from the one who had died (Neimeyer, 2015). Importantly, cognitive behavioural approaches have made increasingly substantial contributions to this 'new look' in bereavement theory, offering evidence that familiar principles of exposure (Bryant et al., 2014), behavioural activation (Papa, Sewell, Garrison-Diehn, \& Rummel, 2013) and cognitive restructuring (Boelen, de Keijser, van den Hout, \& van den Bout, 2007) can alleviate impairments associated with complicated or prolonged disorders of grieving (Prigerson et al., 2009).

The present article extends this effort by reviewing research stemming from the proposition that a central process in grieving is the attempt to reaffirm or reconstruct a world of meaning that has been challenged by loss (Neimeyer, 2001). For the past 15 years, my colleagues and I have taken this clinical observation as a starting point to study the role of meaning making in adaptation to loss, giving rise to a long and multifaceted research program that ultimately has informed and enriched our therapeutic efforts to support the bereaved. My goal in this article is to sketch the contours of this rapidly evolving program through three phases of its development, and to share some of its 'take-home messages' with cognitive behavioural colleagues who join us in this work. I will begin by outlining the major models that underpin our research and practice, then turn to some of the distinctive measures we have constructed and validated to assess the role of meaning in bereavement adaptation, and complete the review with a description of some of the therapeutic methods we are currently evaluating with an international network of collaborators who share the goal of refining a meaning-oriented approach to grief therapy. Finally, I will add a clinical coda that returns to the case of Linda, with which this article opened, to illustrate some of the implications of a meaning reconstruction model in an attempt to bridge the gap that often arises between the domains of research and practice (Neimeyer, Harris, Winokuer, \& Thornton, 2011).

\section{Phase I: Models}

As Linda's case study illustrates, survivors of untimely and tragic loss in particular often struggle to 'make sense' of their loved one's death and its significance for their life. Accordingly, our early work was guided by a cognitive constructivist emphasis on processes of sense making and benefit finding, themes that had informed the work of prior investigators of bereavement adaptation (Davis, Nolen-Hoeksema, \& Larson, 1998). Whereas the former process is usually interpreted in terms of an attempt to comprehend the loss or understand what has occurred, the latter typically entails 
encountering unsought growth through grief, valued life lessons in the experience, or reordered life priorities. Investigating a large group of parents who had lost their children an average of six years before, we found that a struggle with sense making was the most powerful predictor of the level of protracted, anguishing grief symptomatology in the sample, accounting for 5 to 15 times the percentage of variance in normative and complicated grief as other factors studied, such as the passage of time, the gender of the parent, or even the cause of the child's death, whether natural or violent (Keesee, Currier, \& Neimeyer, 2008). Other studies of sense making in the wake of loss generally supported this conclusion, documenting its substantial role in predicting fewer complicated grief symptoms over the first two years of bereavement among young adults (Holland, Currier, \& Neimeyer, 2006; Holland \& Neimeyer, 2010), as well as its prospective prediction of greater wellbeing among older widows and widowers as much as four years after the loss (Coleman \& Neimeyer, 2010). The ability to make sense of the loss also proved to nearly completely mediate the impact of violent death, as through suicide, homicide, and fatal accident, accounting for essentially all of the difference between such deaths and those by natural causes (Currier, Holland, \& Neimeyer, 2006). Moreover, this same ability to find significance in the loss appeared to mitigate complications arising from the death of attachment figures to whom the bereaved were highly bonded (Neimeyer, Baldwin, \& Gillies, 2006). Finding unsought benefits or life lessons in the experience seemed to buffer complicated grief primarily when mourners were otherwise unable to make sense of the experience (Holland et al., 2006).

Despite this accumulating evidence for the role of meaning making in adaptation to bereavement, a broader conceptualisation of meaning systems seemed needed to foster more refined research and to tease out more fully its practice implications. This led us to focus on the role of the self-narrative, understood as 'an overarching cognitive-affective-behavioral structure that organizes the "micro-narratives" of everyday life into a "macro-narrative" that consolidates our self-understanding, establishes our characteristic range of emotions and goals, and guides our performance on the stage of the social world' (Neimeyer, 2004, pp. 53-54). This more narrative view emphasises the need of human beings for a life story that they can make sense of, and that can make sense of them. Faced with the death, and especially the sudden or tragic death, of a key figure in this self-narrative, however, survivors often confront the twin needs to process the event story of the death itself and its implications for their own lives and identity going forward, and to access the back story of their shared lives with their loved one, in a way that reaffirms attachment security and allows them to address unfinished business with the deceased (Neimeyer \& Thompson, 2014). In partial support of the distinction between the event-related and relationship-oriented processing of the loss, the circumstances of the death and the character of the relationship to the deceased have been found to differentially predict traumatic distress and separation distress components of complicated grief symptomatology (Holland \& Neimeyer, 2011). Evidence further suggests that mourners with fragile world assumptions (uncertain belief in the meaningfulness of life, the beneficence of the universe and their own worth; Currier, Holland, \& Neimeyer, 2009) and insecure attachment styles (Meier, Carr, Currier, \& Neimeyer, 2013) have been found to be particularly prone to complications in bereavement, struggling practically, emotionally, and existentially in its aftermath. Among the advantages of this expanded narrative conceptualisation of meaning is that it encourages research on the unique themes in people's accounts of loss (Lichtenthal, Neimeyer, Currier, Roberts, \& Jordan, 2013), and that it 
conjoins naturally with studies of the familial, communal, and cultural narration of loss, placing meaning making in a broader social as well as psychological context (Hooghe, Neimeyer, \& Rober, 2012; Hooghe, Rober, \& Neimeyer, 2011; Neimeyer, Klass, \& Dennis, 2014).

\section{Phase II: Measures}

As useful as the early focus on sense making and benefit finding had been, we encountered serious limitations in the simple self-ratings of these constructs on which both we and other investigators relied. Clearly, more nuanced research on meaning making as a mediator or mechanism of change in grief therapy required multidimensional approaches to measurement, though no such instruments yet existed. Thus, as our research program moved forward, we began to develop and validate several measures of key processes and outcomes implied by the above models, and used them to probe various dimensions of meaning reconstruction in bereavement. Although a discussion of construct, predictive, convergent, factorial, and incremental validity of these measures is beyond the scope of this brief survey, these details, as well as their internal consistency and temporal stability, can be found in both the original articles cited, and in separate brief chapters devoted to each in Techniques of Grief Therapy: Assessment and Intervention (Neimeyer, 2016b). The latter source also provides a full copy of each measure with scoring instructions, and an illustration of its use in clinical settings. Table 1 provides a summary of these measures.

The first such measure we published was the Integration of Stressful Life Experiences Scale or ISLES, which assesses the extent to which survivors of troubling life events or losses are able to integrate them into their overall framework of meaning (Holland, Currier, Coleman, \& Neimeyer, 2010). The scale includes 16 items (e.g., 'I don't understand myself anymore since this loss') with which the respondent indicates agreement or disagreement on a 5-point scale. These in turn factor into two subscales entitled Comprehensibility and Footing in the World, with the latter implying a sense of feeling secure or grounded in a meaningful world. A six-item short form of the ISLES was subsequently developed and validated to retain the same factor structure and incremental validity in predicting complicated grief symptomatology (Holland, Currier, \& Neimeyer, 2014), which can be useful in routine clinical assessment as well as research. For example, meaning making as measured by the ISLES has been found to be the leading risk factor for anguished anticipatory grief in family members of Veterans in palliative care, eclipsing the role of spiritual struggle, relational dependency, anxiety proneness, and low education (Burke et al., 2015). Ineffective meaning making also appears to mediate between spiritual crisis in bereavement and complicated grief as an outcome in a group of religiously inclined mourners (Lichtenthal, Burke, \& Neimeyer, 2011).

Complementing the ISLES, we also developed the Grief and Meaning Reconstruction Inventory (GMRI) to assess not so much the extent of meaning making about a loss, as the thematic content of meanings made (Gillies, Neimeyer, \& Milman, 2015). Grounded in an extensive qualitative study of the narratives of a diverse group of adults grieving the loss of several types of relationships to various causes of death, the GMRI consists of 29 items (e.g., 'Since this loss, I am more self-reflective') rated for degree of agreement on a 5-point scale. Items are grouped into five interpretable subscales, measuring Continuing Bonds, Personal Growth, Sense of Peace, Emptiness and Meaninglessness, and Valuing Life. The GMRI therefore offers a convenient way 
TABLE 1

Measures of Meaning in Bereavement

\begin{tabular}{|c|c|c|c|c|}
\hline Title of measure & Authors & Items & Focus & Subscales \\
\hline $\begin{array}{l}\text { Integration of } \\
\text { Stressful Life } \\
\text { Experiences } \\
\text { Scale (ISLES) }\end{array}$ & $\begin{array}{l}\text { Holland, } \\
\text { Currier, } \\
\text { Coleman, \& } \\
\text { Neimeyer } \\
\text { (2010) }\end{array}$ & 16 & $\begin{array}{l}\text { Extent of meaning } \\
\text { made of loss }\end{array}$ & $\begin{array}{l}\text { Comprehensibility, } \\
\text { Footing in the } \\
\text { World }\end{array}$ \\
\hline $\begin{array}{l}\text { Integration of } \\
\text { Stressful Life } \\
\text { Experiences } \\
\text { Scale Short } \\
\text { Form (ISLES-SF) }\end{array}$ & $\begin{array}{l}\text { Holland, } \\
\text { Currier, \& } \\
\text { Neimeyer } \\
\text { (2014) }\end{array}$ & 6 & $\begin{array}{l}\text { Extent of meaning } \\
\text { made of loss }\end{array}$ & $\begin{array}{l}\text { Comprehensibility, } \\
\text { Footing in the } \\
\text { World }\end{array}$ \\
\hline $\begin{array}{l}\text { Grief and } \\
\text { Meaning } \\
\text { Reconstruction } \\
\text { Inventory } \\
\text { (GMRI) }\end{array}$ & $\begin{array}{l}\text { Gillies, } \\
\text { Neimeyer, \& } \\
\text { Milman } \\
\text { (2015) }\end{array}$ & 29 & $\begin{array}{l}\text { Thematic content } \\
\text { of meaning } \\
\text { made of loss }\end{array}$ & $\begin{array}{l}\text { Continuing Bonds, } \\
\text { Personal Growth, } \\
\text { Sense of Peace, } \\
\text { Emptiness and } \\
\text { Meaninglessness, } \\
\text { Valuing Life }\end{array}$ \\
\hline $\begin{array}{l}\text { Inventory of } \\
\text { Complicated } \\
\text { Spiritual Grief } \\
\text { (ICSG) }\end{array}$ & $\begin{array}{l}\text { Burke, } \\
\text { Neimeyer, } \\
\text { Holland, } \\
\text { Dennard, } \\
\text { Oliver, \& } \\
\text { Shear } \\
(2014)\end{array}$ & 18 & $\begin{array}{l}\text { Struggle for } \\
\text { spiritual } \\
\text { meaning in loss }\end{array}$ & $\begin{array}{l}\text { Insecurity with God, } \\
\text { Disruptions in } \\
\text { Religious Practice }\end{array}$ \\
\hline $\begin{array}{l}\text { Meaning in Loss } \\
\text { Codebook } \\
\text { (MLC) }\end{array}$ & $\begin{array}{l}\text { Gillies, } \\
\text { Neimeyer, \& } \\
\text { Milman } \\
\text { (2014) }\end{array}$ & NA & $\begin{array}{l}\text { Coding of } \\
\text { meaning } \\
\text { themes in loss } \\
\text { narratives }\end{array}$ & $\begin{array}{l}30 \text { distinct } \\
\text { categories of } \\
\text { meanings made }\end{array}$ \\
\hline
\end{tabular}

to assess specific sources of meaning in a given mourner's adaptation to the loss, as well as points of vulnerability.

One frequent observation in our previous studies was the extent to which mourners attempted to find meaning in the death of loved ones in spiritual terms, sometimes succeeding and sometimes struggling in their efforts to do so. Spiritual coping and crisis were most evident when the deaths were inherently tragic, as in the deaths of children (Lichtenthal et al., 2011; Lichtenthal, Currier, Neimeyer, \& Keesee, 2010) or through the homicide of a loved one (Burke, Neimeyer, McDevitt-Murphy, Ippolito, \& Roberts, 2011). This observation suggested the need for a bereavementspecific measure of spiritual coping with loss, beyond the generic scales on which the field had depended to that time. Conducting a close content analysis of both written narratives and focus group feedback by spiritually inclined mourners (Burke, Neimeyer, Young, \& Piazza-Bonin, 2014), we developed and validated the Inventory of Complicated Spiritual Grief (ICSG; Burke, Neimeyer, Holland et al., 2014), which contains 18 items (e.g., 'I no longer feel safe and protected by God') that are rated for how true they are to the respondent on a 5-point scale. The ICSG factors into two subscales, which measure Insecurity with God and Disruptions in Religious Practice, reflecting a spiritual struggle in the mourner's relationship to the divine and to the 
faith community. Perturbations in grievers' religious meaning systems, as measured by the ICSG, have proven predictive of their level of anticipatory grief over loved ones at the end of life (Burke et al., 2015) and similarly predict post-loss levels of complicated grief even after the circumstances of the death and generic measures of spiritual coping have been taken into account (Burke, Neimeyer, Holland et al., 2014). However, it should be noted that the ICSG was constructed to assess the experience of Christian mourners and therefore should be used with other samples (especially beyond the other monotheistic Abrahamic traditions of Judaism and Islam) with caution.

Finally, in keeping with a narrative conception of meaning making in bereavement, we have developed the Meaning in Loss Codebook (MLC), a reliable coding system for identifying a set of 30 themes that can be observed in mourners' attempts to make sense of their loss (Gillies, Neimeyer, \& Milman, 2014). Encompassing both positive (e.g., Compassion, Acceptance, Affirmation of the Deceased) and negative categories (e.g., Negative Affect, Regret, Lost Identity), the MLC might be used to code survivor accounts, psychotherapy transcripts, grief blogs, or even published texts from different cultures or historical eras for the nuanced meanings they invoke in reference to a loss, though extension to narratives of different forms or focus could well require refinement or extension of the basic categories.

In sum, this second generation of measures permits investigators and clinicians to conduct a nuanced assessment of the status of mourners' meaning systems as they contend with loss and adapt to life in its aftermath. It also sets the stage for more informative research on meaning reconstruction processes and outcomes in grief therapy, permitting assessment of presumed mechanisms of change, as well as detection of unique themes in client meaning making that require more careful evaluation or intervention.

\section{Phase III: Methods}

With a growing evidence base for the relevance of a meaning making model in bereavement and an enlarged toolbox of measures for assessing its core processes, we are currently turning to the construction and evaluation of a range of therapeutic methods for fostering meaning reconstruction in the wake of loss. One example is the Mustard Seed Project, a weekend workshop integrating a narrative constructivist approach to therapy with Buddhist dharma lessons on the nature of suffering, impermanence, and a fluid conception of self. Implemented by constructivist psychologists working in tandem with Buddhist monks as co-therapists, the program intersperses mindful meditation, alternation between 'self-immersive' presentation of members' loss narratives to a partner and 'self-distancing' relating of that story by the partner to the group, and expressive arts work drawing on poetry and creative writing to promote perspective taking and narrative revision. Results of an open trial of two such workshops for bereaved adults document a reduction in grief-related suffering, enhancement of meaning made on the ISLES, and reports of personal growth on the part of participants (Neimeyer \& Young-Eisendrath, 2015).

A second line of investigation focuses on Directed Journaling (Lichtenthal \& Neimeyer, 2012) to facilitate meaning making, by prompting clients to reflect on how they have made sense of their loss, the philosophic and personal resources that have contributed to their resilience, and unsought gifts in grief and life lessons for which they are grateful. Building on evidence for the efficacy of this intervention in a randomised 
controlled trial (Lichtenthal \& Cruess, 2010), Laurie Burke, Melissa Smigelsky and I are currently collaborating with Michelle Pearce and Debra Wiegand of the University of Maryland to test the effectiveness of journalling, drawing on the spiritual beliefs of religiously inclined mourners in addressing both their complicated grief and spiritual struggle as assessed by the ICSG. Notably, this intervention, like the Buddhist-oriented Mustard Seed Project, is appropriate for mourners of any religious background. Its implementation on the internet over the span of a single week of prompted journalling is targeted toward the design of brief meaning-oriented interventions that foster resilience, whether used in conjunction with professional counselling or as a freestanding activity.

Drawing on these and other narrative procedures, we subsequently devised a distinctive Meaning in Loss Group structure spanning 12 sessions of weekly contact (see Table 2). In keeping with the meaning reconstruction model of grieving described above, sessions are divided into groups of modules that promote both (a) processing of the 'event story' of the loss and its implications for the survivor's life, and (b) accessing and affirmation of the 'back story' of the relationship with the deceased to enhance continuity and security in the mourner's self-narrative (Neimeyer \& Thompson, 2014). For example, after introducing the deceased (Hedtke, 2012), early sessions feature a loss timeline for depicting significant life transitions (Dunton, 2012), and when indicated restorative retelling procedures, an exposure-based review of the traumatic death story to foster its fuller processing and integration (Neimeyer, 2012b; Saindon et al., 2014). Similarly, later sessions facilitate reconstruction of the attachment bond with the loved one in modules devoted to imaginal letter writing to and from the deceased (Neimeyer, 2012a) and the exploration of their life imprint on the vocation, lifestyle, and values of the group members (Neimeyer, 2010). Closing sessions use symbolic virtual dream stories (Neimeyer, Torres, \& Smith, 2011) and group rituals (Doka, 2012) to validate the work done and project into a hopeful future. Sessions make use of a recurrent structure featuring dyadic interaction among members, followed by whole group processing to promote high levels of empathy and engagement, as well as homework of both a reflective and action-oriented character. Periodic psychoeducation about theories of grief (e.g., shattered assumptions; the Dual Process model of coping) and sources of meaning (e.g., creative and spiritual) are used to scaffold assignments to confront avoidance, extend the loved one's legacy, and rebuild a life of purpose and meaning.

An initial successful trial of the Meaning in Loss Group (MLG) format was carried out with a heterogeneous group of bereaved adults at the Jewish General Hospital of Montreal in collaboration with Evgenia (Jane) Milman, who served as therapist under my weekly supervision. A second is now underway at the Medical University of South Carolina, again with Milman as therapist, under the direct supervision of Alyssa Rheingold. Notably, the latter implementation of the MLG makes use of enhanced exposure and behavioural activation procedures, in keeping with other contemporary cognitive behaviour therapy models. Likewise, a third trial of this group structure at the University of Roehampton in the United Kingdom, spearheaded by Edith Steffen, is currently under development, giving greater attention to culturally specific means of conserving and extending the continuing bond with the deceased in a life-affirming fashion. As a meaning reconstruction approach is not conceived of as a specific theory competing with other models, but rather as a 'meta-theory' that can potentially inform many approaches to grief therapy (Neimeyer, 2015), such creative adaptation of its basic structure is altogether welcome. 


\section{TABLE 2}

Meaning in Loss Group Structure

\begin{tabular}{|c|c|c|c|}
\hline Session & Phase & Technique & Summary description \\
\hline 1 & Introduction & & $\begin{array}{l}\text { Introductions, reminders regarding } \\
\text { confidentiality, and group norm } \\
\text { setting. Discuss common worries, } \\
\text { hopes, and goals of participants } \\
\text { regarding their involvement in the } \\
\text { group, using dyadic sharing followed } \\
\text { by plenary group processing. }\end{array}$ \\
\hline
\end{tabular}

2

Reopening the
Story

3

$$
\begin{aligned}
& \text { Processing the } \\
& \text { Event Story } \\
& \text { of the Loss }
\end{aligned}
$$

4

5

$$
\begin{aligned}
& \text { Exploring } \\
& \text { Sources of } \\
& \text { Meaning } 1
\end{aligned}
$$
Introducing the Loved One

Loss Time Line
Meaning Re- construction Interview
Hello Again
Letter

Invite group members to introduce the group to the deceased, reviewing the character of the relationship during life and validating the loved one's special qualities. Invite the group members to share meaningful objects related to the deceased.

On paper, plot life trajectory, including significant points of transition and loss, noting emotional response to each and symbolising or naming different life 'chapters'. Share with partner, who then reports to the group. Plan one concrete step to take in the next week in a hopeful or healing direction.

In dyads, sift through account of the loss, using Entry, Experiencing, Explanation and Elaboration Questions, adding Restorative Retelling emphasis when death was traumatic.

Introduce and discuss the Dual Process Model of Coping and the Shattered Assumptions Model as potential guides for interpreting and, thus, making meaning of the loss experience. Introduce the Hello Again Letter as an activity to complete between sessions. Practise one 'restoration oriented' activity in the week to come.

Reopen the dialogue with the deceased through discussion and sharing of the Hello Again Letter. This letter addresses the relationship with the deceased prompted by 'conversation starters' offered by the therapist. Introduce the Letter From Loved One as an activity to complete between sessions. Plan one activity to address something one has been avoiding. 
Table 2

Continued

\begin{tabular}{|c|c|c|c|}
\hline Session & Phase & Technique & Summary description \\
\hline 7 & & $\begin{array}{l}\text { Letter from } \\
\text { Loved One }\end{array}$ & $\begin{array}{l}\text { Continue dialogue with the deceased } \\
\text { by sharing and discussing the Letter } \\
\text { from Loved One. This letter takes the } \\
\text { form of a response from the loved } \\
\text { one (written by the bereaved) to the } \\
\text { Hello Again letter, typically } \\
\text { reaffirming love and support in } \\
\text { moving forward with life. Introduce } \\
\text { the Life Imprint as an activity to } \\
\text { complete between sessions, and } \\
\text { consider action stemming from it. }\end{array}$ \\
\hline 8 & & Life Imprint & $\begin{array}{l}\text { Share and discuss the Life Imprint } \\
\text { exercise, which entails an exploration } \\
\text { of the lasting impact of deceased on } \\
\text { the group member's identity, life, and } \\
\text { values. }\end{array}$ \\
\hline 9 & $\begin{array}{l}\text { Exploring } \\
\text { Sources of } \\
\text { Meaning } 2\end{array}$ & & $\begin{array}{l}\text { Discuss spiritual and creative } \\
\text { responses to loss. Introduce dreams } \\
\text { and 'sense of presence' as sources of } \\
\text { meaning. }\end{array}$ \\
\hline 10 & Consolidation & $\begin{array}{l}\text { Virtual Dream } \\
\text { Story }\end{array}$ & $\begin{array}{l}\text { Introduce and lead participants through } \\
\text { the Virtual Dream Story, then share } \\
\text { and discuss this experience. This } \\
\text { exercise entails writing a symbolic } \\
\text { story about loss to place the death in } \\
\text { perspective and consider its } \\
\text { implications for future. }\end{array}$ \\
\hline 11 & Termination & & $\begin{array}{l}\text { Discuss and prepare for the impending } \\
\text { end of the group. Decide on an } \\
\text { end-of-group ritual to be carried out } \\
\text { in the final session. }\end{array}$ \\
\hline 12 & & Ending Ritual & $\begin{array}{l}\text { Recap the group members' } \\
\text { experiences. Revisit therapeutic } \\
\text { goals and discuss the future. Carry } \\
\text { out ending ritual. }\end{array}$ \\
\hline
\end{tabular}

A further innovative implementation of this same modular structure is currently being evaluated in a randomised trial being undertaken in collaboration with Daniela Alves and Miguel Gonçalves of the University of Minho in Portugal. In this instance, we first trained a cadre of constructivist psychologists in the principles and practices of meaning reconstruction, and then paired them with clients who met criteria for complicated grief recruited throughout Portugal and Brazil. Each therapist then met weekly with the bereaved in individual videoconference sessions to conduct virtual therapy, augmented by emailed narrative assignments. As we near the midpoint in data collection, the program appears to be clearly acceptable to participants and stimulating for therapists, who are greatly augmenting their therapeutic toolbox, as well as gaining experience in conducting a form of 'therapy without borders' in a 
virtual world. As with the group trials described above, the bereaved adults who have participated in the virtual version of the program have frequently suffered highly traumatising losses such as the suicide of a loved one or the drug overdose of a child. Nonetheless, attrition in all cases has been conspicuously low, and clients report high satisfaction with the group, as well as encouraging movement toward enhanced meaning and reduced bereavement complications. Completion of this randomised trial will, of course, permit more systematic evaluation of the program's efficacy and acceptability.

Finally, we also have utilised a mixed methods multiple case study design to study the generation of change in session-by-session analyses of master therapists working with bereaved clients across six sessions of videotaped constructivist, personcentred and existential psychotherapy (Alves, Mendes, Gonçalves, \& Neimeyer, 2012; Piazza-Bonin, Neimeyer, Alves, Smigelsky, \& Crunk, 2016; Piazza-Bonin, Neimeyer, Alves, \& Smigelsky, 2016). Coding Innovative Moments (IMs) in which clients clearly depart from the dominant narrative of their grief, we have in each therapy reliably identified instances of IMs centring on reflection, protest, action, reconceptualisation and performing change, and traced their relationship to weekly improvement in client functioning. The results have documented clear trends linking the process and timing of narrative revision with the proximal outcome of therapy, laying the groundwork for future research that will explore the linkages between specific therapeutic procedures, the production of innovative moments in the course of therapy, and ultimately, reductions in clients' grief-related suffering. We are optimistic that the dovetailing of such process-outcome studies with more conventional clinical trails will contribute to the identification of the 'active ingredients' of a meaning reconstruction approach, permitting the development of still more precise and promising therapeutic methods.

\section{A Clinical Coda}

Toward the end of our first session of therapy, I inquired about how Linda managed the cascade of grief and trauma symptoms she had described, and learned of the important role of music in her life as a means of expressing and modulating difficult emotions, drawing on a great range of artists and genres. I therefore wondered aloud about whether she might be interested in constructing a playlist of significant songs that traced the arc of her relationship with Mark, from their first encounter through the development of their special intimacy, to the point of his tragic death and beyond, into her bereavement. Linda readily agreed, and in response to my question, 'What might be the value of that?', she noted, 'I'm in disarray, and that would give it all a kind of order ... like something you can put a name on.' Discussing the place and time that would provide her a sense of safety in undertaking this potentially emotional task, we closed the session with this homework as a first small attempt to both honour the 'back story' of Linda's relationship with Mark, and discern meaning and pattern

74 in the 'event story' of his death. In leaving, Linda noted that she felt 'tired' but also 'hopeful' for the first time in six months.

At the beginning of our second session, Linda eagerly shared her playlist, which she had separated into two parts: before and after Mark's accident. In the first, she featured a series of songs that captured their flirtation, their passion and the 'fun' of shared adventures, culminating ominously in a song about 'Tennessee Whiskey' that referred to the onboard drinking that was implicated in her lover's ill-fated dive into shallow water. Significantly, many of the songs she chose featured country artists - a 
salute to Mark's working-class background, and also because, as Linda explained, 'country music is all about loss'. In contrast, she switched to stirring orchestral music after the accident to better capture the wordlessness and raw emotionality of her grief, a part of the project she expected to extend as she moved forward in her life.

In this same session we began the restorative retelling procedure that would provide the primary structure for our remaining five sessions. This 'slow motion' review of the story of Mark's accident, hospitalisation and death involved three interbraided processes: bracing, pacing, and facing (Neimeyer, 2016c). Bracing entails first grounding the client in the session through establishing a strong empathic bond, as well as by revisiting and reaffirming in a preliminary way the personal, relational and philosophic or spiritual resources on which he or she could draw in tolerating a review of the narrative of the loss. Pacing involves dosing exposure to the story's difficult details, staying present to them, without avoidance, to process what arises. Finally, facing implies compassionate confrontation with the experience and its associated meanings and emotions, with the therapist serving as witness, as the client seeks some level of empowerment in a tragically disempowering event. In practical terms, this often involved devoting 30-45 minutes of the therapeutic hour to a close review of the story of the death, visualising the scenes as they unfolded, in this case assisted by the holiday photos and video clips that Linda had readily available on her phone, which were followed by her virtual documentary of Mark's hospitalisation as well. In the course of the retelling, I gently diverted Linda's attention to the external, internal and reflexive narrative, that is, to what happened, how it felt and what it meant, through timely recursive questions. Subsequent in-session and between-session processing under carefully negotiated conditions of safety (e.g., further therapeutic journalling in a comforting space about feelings or insights prompted by the review) then further facilitated the integration of the experience.

Significantly, Linda set the stage for the 'event story' of the boating accident with a relational 'back story' describing her long drive with Mark to the lake, illustrated with uncanny and uncharacteristic candid snapshots of his gazing pensively skyward, images of the foreboding storm clouds that rolled in as they settled in for the evening, and other evocative images that in hindsight felt like an ominous foreshadowing of the tragedy to follow. Underscoring this visual track, Linda's recollections of their final evening (watching the film Tombstone) and their last words before boarding the vessel (expressing gratitude for the emerging sun on 'a perfect day') added poignancy to the account that followed. Tears flowed as the account moved forward to the fateful dive that broke Mark's neck — innocently recorded in video — and the frantic rescue that followed. As emotions crested, we metaphorically 'pressed pause' on the retelling, closing our eyes as I joined her in 'breathing through' the strong affect, labelling the feelings, and giving voice to the meanings braided together with the events. In the closing 15 minutes of the session we mindfully 'cleared the screen', opened our eyes, and processed Linda's reactions. The strongest of these was her brave acknowledgment: 'I don't want to forget it, and I feared I would ... I want to go home and write the whole story down, to archive it, along with my feelings and thoughts, and weave them into the narrative.' We then discussed the principles of self-care that would allow her to do so safely, as she thoughtfully planned a ritual setting for her directed journalling (e.g., lighting a special candle on a silver tray on her desk, placed alongside Mark's picture). The next four sessions greatly deepened this beginning, as we slowed the account considerably to retell critical moments in the hospital involving significant others, anguished conversations with Mark about 
his quadriplegia, failing respiration and dying, pivotal medical decision making, and ultimately, the death that his physicians could not forestall. Throughout, we tacked from the external narrative of what Linda heard and saw, sometimes illustrated by a photo that immersed her once again in a compelling scene, to the internal narrative of her emotional and bodily feelings, and to the reflexive, meaning-oriented narrative that addressed lingering questions while affirming undying love.

In our final, sixth session, Linda brought in a further narrative exercise I had suggested and that she had quickly accepted: writing a 'letter to God' as homework, which gave voice to her anger, incomprehension, fear that Mark's death was some form of divine retribution for her lack of faith, and her need to 'lay low' and withdraw from a being she viewed as unpredictable and inconsistent at best and malicious at worst. Engaging with the questions together, without simple answers, Linda began to envision a way forward by confiding about her spiritual struggle with a wise and compassionate friend who she trusted could help her sort through her crisis of faith and gradually feel her way toward a changed, but resilient world view.

Concluding our therapy, Linda summarised where she had come as a result of the work of the previous sessions: 'It feels good to remember even the small details, about Mark and about those awful days. I don't feel as heavy walking around as I did before.... My mind isn't as cluttered and disorganized. For months, I couldn't make sense of it, or figure out what happened. Now I'm able to think of each piece, and process them .... I can even laugh now, and make weird jokes with my friends. You made even the bad things easier to live with.'

\section{Conclusion}

Over the past decade, a growing network of investigators has collaborated to devise, test and refine models, measures and methods for conceptualising, tracing and facilitating the process of meaning reconstruction in grief therapy. We are encouraged by the progress in this research program to date, and are hopeful that this work will contribute to a more compassionate understanding of the challenges faced by people whose worlds of meaning have been challenged by loss. Equally, we hope that our efforts, like those of others developing theoretically grounded and evidence-informed interventions (Boelen et al., 2007; Bryant et al., 2014; Papa et al., 2013; Shear et al., 2014), will support the efforts of therapists in many nations to alleviate the anguish of those living with prolonged and complicated grief.

\section{References}

Alves, D., Mendes, I., Gonçalves, M., \& Neimeyer, R.A. (2012). Innovative moments in grief therapy: Reconstructing meaning following perinatal death. Death Studies, 36, 785-818.

Boelen, P.A., de Keijser, J., van den Hout, M., \& van den Bout, J. (2007). Treatment of complicated grief: A comparison between cognitive-behavioral therapy and supportive counseling. Journal of Clinical and Consulting Psychology, 75, 277-284.

Bryant, R., Kenny, L., Joscelyne, A., Rawson, N., Maccallum, F., Cahill, C., ... Nickerson, A. (2014). Treating prolonged gried disorder: A randomized clinical trial. Journal of the American Medical Association Psychiatry. doi:10.1001/jamapsychiatry.2014.1600

Burke, L.A., Neimeyer, R.A., Smigelsky, M.A., Gibson, B.W., Ali, K.S. \& Clark, K.A. (2015). Risk factors for anticipatory grief in family members of terminally ill Veterans receiving palliative care services. Journal of Social Work in End-of-Life $\mathcal{E}$ Palliative Care, 11:3-4, 244-266, DOI: 10.1080/15524256.2015.1110071. 
Burke, L.A., Neimeyer, R.A., Holland, J.M., Dennard, S., Oliver, L., \& Shear, M.K. (2014). Inventory of Complicated Spiritual Grief: Development and validation of a new measure. Death Studies, 38, 239-250. doi:10.1080/07481187.2013.810098

Burke, L.A., Neimeyer, R.A., Young, A.J., \& Piazza-Bonin, E. (2014). Complicated spiritual grief II: A deductive inquiry following the loss of a loved one. Death Studies, 38, 268-281. doi:10.1080/07481187.2013.829373

Burke, L.A., Neimeyer, R.A., McDevitt-Murphy, M.E., Ippolito, M.R., \& Roberts, J.M. (2011). Faith in the wake of homicide: Spiritual crisis and bereavement distress in an African American sample. International Journal for the Psychology of Religion, 21, 289-307.

Coleman, R.A., \& Neimeyer, R.A. (2010). Measuring meaning: Searching for and making sense of spousal loss in later life. Death Studies, 34, 804-834.

Currier, J.M., Holland, J.M., \& Neimeyer, R.A. (2006). Sense making, grief and the experience of violent loss: Toward a mediational model. Death Studies, 30, 403-428.

Currier, J.M., Holland, J.M., \& Neimeyer, R.A. (2009). Assumptive worldviews and problematic reactions to bereavement Journal of Loss and Trauma, 14, 181-195.

Davis, C.G., Nolen-Hoeksema, S., \& Larson, J. (1998). Making sense of loss and benefiting from the experience: Two construals of meaning. Journal of Personality and Social Psychology, 75, $561-574$.

Doka, K. (2012). Therapeutic ritual. In R.A. Neimeyer (Ed.), Techniques of grief therapy: Creative practices for counseling the bereaved (pp. 341-343). New York: Routledge.

Dunton, A.J. (2012). Loss timelines. In R.A. Neimeyer (Ed.), Techniques of grief therapy (pp. 184186). New York: Routledge.

Gillies, J., Neimeyer, R.A., \& Milman, E. (2014). The Meaning of Loss Codebook: Construction of a system for analyzing meanings made in bereavement. Death Studies, 38, 207-216. doi: $10.1080 / 07481187.2013 .829367$

Gillies, J., Neimeyer, R.A., \& Milman, E. (2015). The Grief and Meaning Reconstruction Inventory: Initial validation of a new measure. Death Studies, 39, 61-74.

Hedtke, L. (2012). Introducing the deceased. In R.A. Neimeyer (Ed.), Techniques of grief therapy: Creative practices for counseling the bereaved (pp. 253-255). New York: Routledge.

Holland, J.M., Currier, J.M., \& Neimeyer, R.A. (2006). Meaning reconstruction in the first two years of bereavement: The role of sense-making and benefit-finding. Omega, 53, 173-191.

Holland, J.M., Currier, J.M., \& Neimeyer, R.A. (2014). Validation of the Integration of Stressful Life Experiences Scale - Short Form in a bereaved sample. Death Studies, 38, 234-238. doi:10.1080/07481187.2013.829369

Holland, J.M., Currier, J.M., Coleman, R.A., \& Neimeyer, R.A. (2010). The Integration of Stressful Life Experiences Scale (ISLES): Development and initial validation of a new measure. International Journal of Stress Management, 17, 325-352.

Holland, J.M., \& Neimeyer, R.A. (2010). An examination of stage theory of grief among individuals bereaved by natural and violent causes: A meaning-oriented contribution. Omega, 61, $105-122$.

Holland, J.M., \& Neimeyer, R.A. (2011). Separation and traumatic distress in prolonged grief: The role of cause of death and relationship to the deceased. Journal of Psychopathology and Behavioral Assessment, 33, 254-263.

Hooghe, A., Neimeyer, R.A., \& Rober, P. (2012). 'Cycling around an emotional core of sadness': Emotion regulation in a couple after the loss of a child. Qualitative Health Research, 22, 1220-1231.

Hooghe, A., Rober, P., \& Neimeyer, R.A. (2011). The complexity of couple communication in bereavement: An illustrative case study. Death Studies, 35, 905-924.

Keesee, N.J., Currier, J.M., \& Neimeyer, R.A. (2008). Predictors of grief following the death of one's child: The contribution of finding meaning. Journal of Clinical Psychology, 64, 1145-1163.

Kosminsky, P., \& Jordan, J.R. (2016). Attachment informed grief therapy. New York: Routledge.

Lichtenthal, W.G., Burke, L.A., \& Neimeyer, R.A. (2011). Religious coping and meaning-making following the loss of a loved one. Counseling and Spirituality, 30, 113-136. 
Lichtenthal, W.G., \& Cruess, D.G. (2010). Effects of directed written disclosure on grief and distress symptoms among bereaved individuals. Death Studies, 34, 475-499.

Lichtenthal, W.G., Currier, J.M., Neimeyer, R.A., \& Keesee, N.J. (2010). Sense and significance: A mixed methods examination of meaning-making following the loss of one's child. Journal of Clinical Psychology, 66, 791-812.

Lichtenthal, W.G., \& Neimeyer, R.A. (2012). Directed journaling to facilitate meaning making. In R.A. Neimeyer (Ed.), Techniques of grief therapy (pp. 161-164). New York: Routledge.

Lichtenthal, W.G., Neimeyer, R.A., Currier, J.M., Roberts, K., \& Jordan, N. (2013). Cause of death and the quest for meaning after the loss of a child. Death Studies, 37, 327-342.

Meier, A.M., Carr, D.R., Currier, J.M., \& Neimeyer, R.A. (2013). Attachment anxiety and avoidance in coping with bereavement: Two studies. Journal of Social and Clinical Psychology, 32, 315-334.

Neimeyer, R.A. (Ed.). (2001). Meaning reconstruction and the experience of loss. Washington, DC: American Psychological Association.

Neimeyer, R.A. (2004). Fostering posttraumatic growth: A narrative contribution. Psychological Inquiry, 15, 53-59.

Neimeyer, R.A. (2010). The life imprint. In H. Rosenthal (Ed.), Favorite counseling and therapy techniques. New York: Routledge.

Neimeyer, R.A. (2012a). Correspondence with the deceased. In R.A. Neimeyer (Ed.), Techniques of grief therapy (pp. 259-261). New York: Routledge.

Neimeyer, R.A. (2012b). Retelling the narrative of the death. In R.A. Neimeyer (Ed.), Techniques of grief therapy (pp. 86-90). New York: Routledge.

Neimeyer, R.A. (2015). Treating complicated bereavement: The development of grief therapy. In J. Stillion \& T. Attig (Eds.), Death, dying and bereavement: Contemporary perspectives, institutions and practices (pp. 307-320). New York: Springer.

Neimeyer, R.A. (2016a). Complicated grief: Assessment and intervention. In J. Cook, S. Gold, \& C. Dalenberg (Eds.), APA handbook of trauma psychology. Washington, DC: American Psychological Association.

Neimeyer, R.A. (Ed.). (2016b). Techniques of grief therapy: Assessment and intervention. New York: Routledge.

Neimeyer, R.A. (2016c). You were born, still: The search for meaning in perinatal loss. In K. Doka $\&$ A. Tucci (Eds.). Managing conflict, finding meaning. Washington, DC: Hospice Foundation of America.

Neimeyer, R.A., Baldwin, S.A., \& Gillies, J. (2006). Continuing bonds and reconstructing meaning: Mitigating complications in bereavement. Death Studies, 30, 715-738.

Neimeyer, R.A., Harris, D., Winokuer, H., \& Thornton, G. (Eds.). (2011). Grief and bereavement in contemporary society: Bridging research and practice. New York: Routledge.

Neimeyer, R.A., Klass, D., \& Dennis, M.R. (2014). A social constructionist account of grief: Loss and the narration of meaning. Death Studies, 38, 485-498.

Neimeyer, R.A., \& Thompson, B.E. (2014). Meaning making and the art of grief therapy. In B.E. Thompson \& R.A. Neimeyer (Eds.), Grief and the expressive arts: Practices for creating meaning (pp. 3-13). New York: Routledge.

Neimeyer, R.A., Torres, C., \& Smith, D.C. (2011). The virtual dream: Rewriting stories of loss and grief. Death Studies, 35, 646-672.

Neimeyer, R.A., \& Young-Eisendrath, P. (2015). Assessing a Buddhist treatment for bereavement and loss: The Mustard Seed Project. Death Studies, 39, 263-273.

Papa, A., Sewell, M.T., Garrison-Diehn, , \& Rummel, C. (2013). A randomized controlled trial assessing the feasibility of behavioral activation for pathological grief responding. Behavior Therapy, 44, 639-650. doi:http://dx.doi.org/10.1016/j.beth.2013.04.009

Piazza-Bonin, E., Neimeyer, R.A., Alves, D., Smigelsky, M.A., \& Crunk, E. (2016). Innovative moments in humanistic therapy I: Process and outcome of eminent psychotherapists working with bereaved clients. Journal of Constructivist Psychology. Advance online publication. doi:10.1080/10720537.2015.1118712 
Piazza-Bonin, E., Neimeyer, R.A., Alves, D., \& Smigelsky, M.A. (2016). Innovative moments in humanistic therapy II: Analysis of change across the course of three cases of grief therapy. Journal of Constructivist Psychology. Advance online publication. doi: 10.1080/10720537.2015.1118713

Prigerson, H.G., Horowitz, M.J., Jacobs, S.C., Parkes, C.M., Aslan, M., Goodkin, K., Raphael, B., ... Maciejewski, P.K. (2009). Prolonged grief disorder: Psychometric validation of criteria proposed for DSM-V and ICD-11. PLoS Medicine, 6, 1-12.

Rubin, S.S., Malkinson, R., \& Witztum, E. (2011). Working with the bereaved. New York: Routledge.

Saindon, C., Rheingold, A., Baddeley, J., Wallace, M., Brown, C., \& Rynearson, E.K. (2014). Restorative retelling for violent loss: An open clinical trial. Death Studies, 38, 251-258.

Shear, M.K., Wang, Y., Skriskaya, N., Duan, N., Mauro, C., \& Ghesquiere, A. (2014). Treatment of complicated grief in elderly persons: A randomized clinical trial. Journal of the American Medical Association Psychiatry. doi:10.1001/jamapsychiatry.2014.1242

Stroebe, M., \& Schut, H. (2010). The Dual Process Model of Coping with Bereavement: A decade on. Omega, 61, 273-289. 